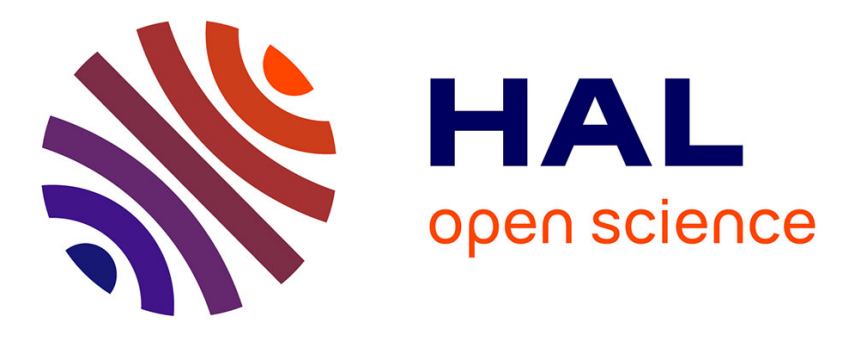

\title{
Advanced age remains an achilles heel for liver resections.
}

Laurent Sulpice, Michel Rayar, Boris Campillo, Claire Pery, Antoine Guillaud, B. Meunier, Karim Boudjema

\section{- To cite this version:}

Laurent Sulpice, Michel Rayar, Boris Campillo, Claire Pery, Antoine Guillaud, et al.. Advanced age remains an achilles heel for liver resections.. World Journal of Surgery, 2014, 38 (4), pp.918-26. 10.1007/s00268-013-2367-0 . hal-00990299

\section{HAL Id: hal-00990299}

\section{https://hal-univ-rennes1.archives-ouvertes.fr/hal-00990299}

Submitted on 13 May 2014

HAL is a multi-disciplinary open access archive for the deposit and dissemination of scientific research documents, whether they are published or not. The documents may come from teaching and research institutions in France or abroad, or from public or private research centers.
L'archive ouverte pluridisciplinaire HAL, est destinée au dépôt et à la diffusion de documents scientifiques de niveau recherche, publiés ou non, émanant des établissements d'enseignement et de recherche français ou étrangers, des laboratoires publics ou privés. 
Advanced age remains an Achilles heel for liver resections.

Laurent Sulpice, $\mathrm{MD}^{1,3}$, Michel Rayar, $\mathrm{MD}^{1}$, , Boris Campillo, $\mathrm{MD}^{2}$, Claire Pery $\mathrm{MD}^{1}$, Antoine Guillaud, MD ${ }^{1}$, Bernard Meunier, $\mathrm{MD}^{1}$ and Karim Boudjema, MD, $\mathrm{PhD}^{1,3}$

1- Service de Chirurgie Hépatobiliaire et Digestive. Centre Hospitalier Universitaire de Rennes, Université de Rennes 1, France

2- INSERM, UMR936, Département d'Information Médicale, Université de Rennes 1, France

3- INSERM, UMR991. Foie, métabolisme et cancer. Université de Rennes1, France

Running title: Liver resection in elderly patients

Key words: Liver resection, elderly patients, mortality

\section{Correspondence}

Docteur Laurent Sulpice

Service de Chirurgie Hépatobiliaire et Digestive, Hôpital Pontchaillou, Centre

Hospitalier Universitaire, Université de Rennes 1, Rennes, France

Email : laurent.sulpice@chu-rennes.fr

Telephone: + 33299288498

Fax: + 33299284129

Word count: 2449

Conflicts of interest: The authors have no conflicts of interest to declare

Funding: The study received no external support 
Author contributions: LS conceived and designed study, undertook the analysis and interpretation of data, and wrote and finalized the manuscript. CP collected data and undertook interpretation of data. BC provided the statistical analysis. MR revised the manuscript, AG collected data and proof-read the manuscript. BM revised the manuscript. KB revised the manuscript and gave final approval for publication. 


\section{ABSTRACT}

Background: As general population is aging, surgery in elderly patients become a major public health issue. This basic question is especially true for liver resection (LR). The aim of this study was to evaluate the operative risks of LR in elderly.

Method: Retrospective analysis of a large recent and monocentric database of LR performed between January 1, 2005 and May 31, 2011. Patients were categorized into 3 groups ( $<60,60$ to 74 and $\geq 75$ years old) to analyze postoperative outcomes as well as 1 year mortality. Clinicopathological factors likely to influence outcomes were assessed by univariate and multivariable analysis.

Results: 1001 consecutive LR were performed in 912 patients (mean age 62 \pm 13 years). The distribution of the LR was $372(37.2 \%), 477$ (47.6\%) and $152(15.2 \%)$ in patients<60 y, 60 to 74 y and $\geq 75$ y old, respectively. The overall morbidity and mortality rates were $33.3 \%$ and $2.5 \%$, respectively. An age $\geq 75$ years was independently associated with postoperative mortality $(\mathrm{OR} 4.75(95 \% \mathrm{Cl}[1.5 ; 15.1] ; \mathrm{p}=0.008)$ and 1-year mortality $\mathrm{OR} 2.8(95 \% \mathrm{Cl}[1.2$; 6.6]; $p=0.015)$, while the rate of postoperative complications $(p=0.216)$, even major complications $(p=0.09)$, was not increased. The other independent risk factors of mortality were a cirrhotic liver $(p=0.017)$, preoperative arterial chemoembolization $(p=0.001)$, caval vein clamping $(p=0.001)$ and intraoperative blood transfusion $(p=0.044)$.

Conclusion: Age beyond 75 years represent a risk factor of death after LR and should be avoided after chemoembolization or in cirrhotic patients. A specific assessment using geriatric indexes might be the key to success in this population. 


\section{INTRODUCTION}

Liver resection $(\mathrm{LR})$ is the most suitable curative treatment for multiple benign and malignant liver diseases. With recent advances in surgical techniques, perioperative management and postoperative care, LR has become increasingly common, and the risks associated with this major procedure have decreased. In Western countries, increased longevity leads to subsequent increasing indications for liver resection in elderly patients.

Recently, an editorial in Lancet (1) emphasized the need to provide the same care to elderly patients and younger patients whenever possible. Many papers have reported the absence of differences between elderly and younger patients in terms of postoperative morbidity and mortality. $(2 ; 3)$

During the last decades, the definition of 'elderly' has evolved. While patients aged less than 60 yrs old are nowadays considered to be young, most of the studies dealing with the impact of age on postoperative outcome have focused on the 60-75 yrs interval. Geriatricians now consider 75 years to be the age over which elderly and geriatric management starts.(4) In this setting, the feasibility and benefits of LR in elderly patients remain unclear, due to small sample sizes and the wide period of analysis. While some reports showed higher postoperative mortality and morbidity rates related to age $(5 ; 6)$, others were unable to demonstrate any increasing morbidity or mortality after LR related to aging,(7) especially when the indication of LR was colorectal metastases(8) (CRM) or hepatocellular carcinoma(9).

The aim of this study was to analyze the outcomes after LR including the 1-year mortality in a large recent and monocentric series of patients with a special focus on age. Secondary objectives were to identify predictors of postoperative mortality that may be corrected preoperatively to decrease the risks of postoperative complications after LR in elderly patients. 


\section{PATIENTS AND METHODS}

\section{Patients}

The study population included all of the consecutive liver resections (LR) without biliary anastomosis that were performed at a single tertiary referral center between January 2005 and May 2011. The clinical data were retrospectively collected from a liver resection database and analyzed after Institutional Review Board approval was obtained. (Opinion $\mathrm{n}^{\circ}$ 12-60)

\section{Preoperative assessment, surgical procedure and perioperative care}

Before surgery, each patient was evaluated by a thoracoabdominopelvic computed tomography (CT) scan with intravenous contrast. A measure of the future liver remnant volume (LRV) was performed when required, and portal vein embolization was performed when the LRV/Total liver volume ratio was $<35 \%$. For malignant diseases, patients were considered to be curable if the tumors could be resected with macroscopically negative surgical margins.

All LR were performed as open or laparoscopic procedures by senior hepatic surgeons. Continuous or intermittent pedicle clamping (Pringle maneuver), or selective clamping of the pedicles for the segment to be resected, was performed in most cases. Two closed-suction drains were placed in the resection space and removed on the fifth post-operative day (POD) when drainage was minimal, serous and non-bilious.

The resections were categorized according to the International Hepato-Pancreato-Biliary Association classification for liver resections ((IHPBA, Brisbane 2000) i.e. resection of (i) two or less, (ii) three and four or (iii) more than four segments were defined as (i) minor (including wedge resection) (ii) major or (iii) extended hepatectomies, respectively.(10) 
All patients received antibiotic prophylaxis. A daily subcutaneous injection of low-molecularweight heparin sodium was started as a prophylactic against deep venous thrombosis on POD 1.

\section{Collected data}

The preoperative data included general patient characteristics (age, sex and BMI score, cirrhosis), prior surgical history and primary tumor histopathology.

The perioperative data consisted of the operation duration, pedicle clamping or selective clamping of the pedicles for vascular resection when needed, vena caval clamping, concomitant abdominal surgery, and transfusion needs.

The postoperative data included the hospital length of stay (HLS), need for intensive care, reoperations, and rehospitalization. Liver failure was defined by the " $50-50$ " syndrome on postoperative day 5 (including serum bilirubin $>50 \mu \mathrm{mol} / \mathrm{L}$ and prothrombin time $<50 \%$ ).(11)

Postoperative complications were assessed and classified according to the Clavien-Dindo classification system.(12) Major complications were categorized as grades III-V and were defined as morbidity requiring radiological or surgical intervention. Postoperative mortality was defined as death occurring during the initial hospital stay or within 30 days after surgery if the patient was discharged. The 1-year post-operative mortality was also assessed. 


\section{Statistical analysis}

Statistical analyses were performed with SPSS Statistics 17.0 software for Windows (SPSS Inc., Chicago, IL).

Data from the study population were described either by means and standard deviations or by absolute and relative frequencies, for quantitative and qualitative data, respectively.

To determine the cut-off over which mortality (perioperative and 1-year) was increased, accuracy curves were realized.

To evaluate the cut-off over which mortality and morbidity were increased, we pooled the patients in 3 groups: Less than $60 \mathrm{yrs}, 60$ to $74 \mathrm{yrs}$ and $75 \mathrm{yrs}$ old or older. Patient characteristics, perioperative parameters and outcomes were compared between the 3 groups.

The Chi square test or the Fisher exact test were used to compare qualitative data and the Student's t-test was used to compare quantitative data between groups.

The perioperative and 1-year mortality were studied according to the patient characteristics, including age before liver resection, and perioperative factors. A univariate analysis was performed with the Chi-square test or the Fisher exact test when necessary. Factors associated with death with a $p$ value $<0.2$ were tested in a multiple logistic regression model using the forward selection procedure and the Wald test to assess their independent correlation with mortality. 


\section{RESULTS}

\section{Demographic and operative data}

Between January 2005 and May 2011, 1001 consecutive liver resections were performed in 912 patients (626 men and 286 women). The mean age at the time of resection was $62 \pm 13$ years. Two, three, four, or five successive resections were performed in $70,6,1$ and 1 patients, respectively. Among the LR, 504 (50.3\%) were performed for liver metastasis, 375 $(37.5 \%)$ and $122(12.2 \%)$ for primary liver malignant tumor and benign lesion respectively. The indications for LR are reported in table 1.

The demographic characteristics and operative data in the $<60,60$ to $74 \mathrm{yrs}$, and $\geq 75$ age groups are reported in Table 2 . One hundred and fifty two patients were $\geq 75 \mathrm{yrs}(15.2 \%)$; in this group, patients had a significantly lower BMI and cirrhotic livers were less frequent.

\section{Postoperative mortality (table 3)}

The overall postoperative mortality rate was $2.6 \%$. The distribution of mortality according to the 3 age groups is shown in Figure $1(A)$. The cutoff of age over which perioperative mortality was increased, was represented in figure 2. Among the 15 factors assessed by the univariate analysis, age $\geq 75$ years $(p=0,045)$, cirrhosis $(p=0,008)$, preoperative chemotherapy $(p=0,015)$, preoperative arterial chemoembolization $(p<0,001)$, preoperative portal vein embolization $(p=0,005)$, primary cancer $(p=0,015)$, major hepatectomy $(p=0,005)$, caval vein clamping $(p=0,006)$ and intraoperative blood transfusion $(p=0,013)$ were significantly related to postoperative mortality. On the multivariable analysis, intraoperative blood transfusion $(\mathrm{OR}=2.4$; confidence interval $(\mathrm{Cl}) 95 \%$ [1; 5.5]; $\mathrm{p}=0.044)$, cirrhotic liver $(\mathrm{OR}=3.3 ; \mathrm{Cl} 95 \%$ [1.2; 8.9]; $\mathrm{p}=0.017)$, age $\geq 75 \mathrm{yrs}$ (odds ratio [OR] 4.75; [Cl] 95\% [1.5; 15.1]; $p=0.008)$, preoperative arterial chemoembolization $(\mathrm{OR}=5.5 ; \mathrm{Cl} 95 \%[2 ; 15.3]$; $\mathrm{p}=0.001$ ), and intraoperative caval vein clamping (OR=6.1; $\mathrm{Cl} 95 \%[2.1 ; 17.5] ; \mathrm{p}=0.001)$ remained significant independent risk factors for postoperative death. 


\section{Postoperative complications (tables 4 and 5)}

The overall morbidity rate was $33.3 \%$, without a significant difference between the 3 age groups $(p=0,216)$. There was no significant difference between the 3 groups $(p=0,269)$ in the postoperative complications according to the Clavien-Dindo classification (table 4).

Except for the hospital stay $(p=0,02)$, there were no significant differences between the three groups, regarding the type of complications (table 5).

\section{1-year mortality (table 6)}

The overall 1 -year mortality rate was $5.5 \%$. The distribution of 1 -year mortality according to the 3 groups of age is shown in figure $1(B)$. In the univariate analysis, age $\geq 75$ years $(p=0.018)$, sex (male, $p=0.012)$, cirrhosis $(p<0.001)$, preoperative chemotherapy $(p=0.024)$, preoperative arterial chemoembolization $(p=0.004)$, portal vein embolization $(p=0.01)$, primary cancer $(p<0.001)$, major hepatectomy $(p<0.001)$ and intraoperative blood transfusion $(p=0.001)$ were significantly associated with an increased 1 -year mortality. In the multivariate analysis, age $\geq 75$ years (OR 2.8; Cl 95\% [1.2; 6.6]; $p=0.015)$, cirrhosis (OR=2.6; $\mathrm{Cl} 95 \%$ [1.2; 5.6]; $p=0.013$ ), preoperative arterial chemoembolization (OR=5.5; $\mathrm{Cl} 95 \%$ [2; 15.3]; $\mathrm{p}=0.001)$, primary cancer $(\mathrm{OR}=2.3$; $\mathrm{Cl} 95 \%[1.1 ; 4.6] ; \mathrm{p}=0.026)$, major hepatectomy $(\mathrm{OR}=3$; $\mathrm{Cl} 95 \%[1.5 ; 6] ; \mathrm{p}=0.002)$ and intraoperative blood transfusion $(\mathrm{OR}=2.1 ; \mathrm{Cl} 95 \%[1.1 ; 3.8]$; $p=0.016$ ) remained independent predictive factors of increased 1 -year mortality. 


\section{DISCUSSION}

The main endpoint of the study was to analyze the impact of age on morbidity and mortality after liver resection. The results showed that $\geq 75$ years of age was associated with increased postoperative and 1-year mortality. Preoperative portal vein embolization, chemoembolization, cirrhotic liver, intraoperative blood transfusion and caval vein clamping were also independent predictive factors of increased postoperative and 1-year mortality. No difference was found regarding the postoperative mortality between patients $<60$ years and those aged 60 to 74 years.

Similarly, the present results show that an age over 75 years old was a predictive factor for a longer hospital stay, which is consistent with the results of Cho and colleagues.(13)

Compared with most of the previous studies, this work included a large number of patients resected by expert senior surgeons in a tertiary referral center in a short and recent period. These results may be predictive of the reality of liver surgery in the near future. Indeed, in the beginning of the $21^{\text {st }}$ century, there were approximately 600 million elderly people worldwide, which is three times more than 50 years ago. Within the same period, the elderly population has been aging, with an increasing rate of people $\geq 80$ years old.(14) Due to these changing demographics, the elderly now account for $>60 \%$ of all new cancer cases and $>70 \%$ of cancer deaths.(15) This trend implies an expansion of surgical indications for increasingly older patients.

In spite of the improved outcomes observed at high volume centers due to the advances in surgical management and postoperative care, LR is still associated with an increased mortality in elderly. Our results are consistent with previously reported data showing that the mortality risk after liver resection increased from 2.9 to 6.7 times in patients aged less or more than 75 years, respectively (16). The novelty of our results was based on a higher postoperative mortality rate while postoperative morbidity according to the Clavien-Dindo classification was similar. There was no difference in liver failure or other liver-specific complications, indicating that the livers of elderly patients can tolerate surgery as well as 
younger patients can, as previously described by Cook et al after resection of colorectal liver metastases.(17)

These results go against the idea that success in LR is linked to liver regeneration (LRG). Indeed, in the elderly, it is established that LRG is impaired (18) and delayed.(19) During aging, the liver is subjected to physiological changes such as alterations in hepatocyte morphology(20) and lower blood flow(21). These factors can reduce the liver's tolerance to ischemic damage and can lead to an alteration of liver function during LR.

The imbalance between increased mortality without increasing morbidity reflects the lower possibility of adaption and response to any stress and complications in this subpopulation of patients. Advanced age should not be regarded as an absolute contraindication to hepatic resection, but should encourage a careful selection of surgical candidates. This preoperative selection process should be based on the comorbidities and tumor type thorough preoperative evaluation and a close collaboration between the surgeon, anesthesiologists and geriatricians.

According to our multivariate analysis, 4 other independent risk factors for postoperative mortality were statistically significant: preoperative cirrhosis, preoperative arterial chemoembolization, caval vein clamping and intraoperative blood transfusion. These results strongly suggest that LR should be avoided in elderly patients with cirrhosis and therefore could be discussed for HCC. Nevertheless, Yamada et al (22) reported the short and longterm safety of LR for HCC in super-elderly patients, even those $>80$ years old. $(2 ; 3 ; 23)$ These results might be explained in part by the small sample size $(n=11)$ for the superelderly group as well as selection bias. No patient in the Yamada study had an American Society of Anesthesiologists-Physical Status (ASA-PS) score $\geq 2$. Recently, Ide et al. also emphasized that the mortality rate was similar in young ( $<75$ years) and elderly ( $>75$ years) patients with HCC.(24) They demonstrated that only surgical stress-preoperative risk score (PRS) was linked to postoperative morbidity in elderly.

Referring to our results, LR appears to be safe as long as the liver is non-cirrhotic, a situation that is associated with benign tumors or colorectal liver metastases 
(CRLM).(17;25;26) Regarding the latest indication, the largest series currently published (25) reported $37.8 \%$ morbidity and $5 \%$ mortality rates, which are percentages that are comparable to our results.

Furthermore, the results showed that intraoperative blood transfusion was associated with increased postoperative mortality. These results are in line with the findings of Shiba et al.(27) Patients who received blood transfusion during LR were more likely to have a longer postoperative length of stay and Clavien Grade Illa or more complications.(28) These data emphasize the need to minimize bleeding during LR, which may be facilitated by the management of this condition at a referral center.

The difficulty in gerontosurgery is linked to the evaluation of the physiological status of patients. Aging leads to reduced renal, hepatic, cardiopulmonary functional reserve and nutritional status. The ASA score is widely and often exclusively used, but has proven not to be sensitive enough for elderly patients undergoing major surgery.(29;30) More specific scores should be used in the elderly to better select patients before LR. Using surgery geriatric indices such as the Charlson score $(31 ; 32)$, Cumulative Illness Rating Scale, or Kaplan-Feinstein index (33) might lead to better appraisal of the physiological age. These geriatric indices have proven to be simple, reliable, and sensitive. Unfortunately, these factors could not be assessed in this retrospective study. Indeed, as comorbidities were not available in our liver resection database for the entire population, they could not be analyzed. This lack of data requires us to interpret our results with caution. Besides, this limitation is also encountered in other large retrospective study previously published on the same topic.(25)

In summary, from this large series of LR at one tertiary referral center of liver surgery, we have identified the cut-off age that is closely correlated with an increased risk of mortality. An age over 75 years was independently associated with increased postoperative and 1-year mortality while postoperative morbidity, especially major complications, was not affected. These results may be explained by the loss of responsiveness to stress and complications 
related to age. A careful selection of elderly patients undergoing LR, avoiding patients with cirrhosis; and a specific assessment of the patient's general condition using geriatric indexes might be the key to success in this population. 


\section{REFERENCES}

1. Ageing well: a global priority. Lancet 2012;379(9823)1274.

2. Poon RT, Fan ST, Lo CM, et al. Hepatocellular carcinoma in the elderly: results of surgical and nonsurgical management. Am.J.Gastroenterol. 1999;94(9)2460-2466.

3. Ferrero A, Vigano L, Polastri R, et al. Hepatectomy as treatment of choice for hepatocellular carcinoma in elderly cirrhotic patients. World J.Surg. 2005;29(9)1101-1105.

4. Arai $\mathrm{H}$, Ouchi $\mathrm{Y}$, Yokode $\mathrm{M}$, et al. Toward the realization of a better aged society: messages from gerontology and geriatrics. Geriatr.Gerontol.Int. 2012;12(1)16-22.

5. Menon KV, Al-Mukhtar A, Aldouri A, et al. Outcomes after major hepatectomy in elderly patients. J.Am.Coll.Surg. 2006;203(5)677-683.

6. Figueras J, Ramos E, Lopez-Ben S, et al. Surgical treatment of liver metastases from colorectal carcinoma in elderly patients. When is it worthwhile? Clin.Transl.Oncol. 2007;9(6)392-400.

7. Riffat F, Chu F, Morris DL. Liver resection in octogenarians. HPB (Oxford) 2006;8(3)206-210.

8. de Liguori CN, van Leeuwen $\mathrm{BL}$, Ghaneh $\mathrm{P}$, et al. Liver resection for colorectal liver metastases in older patients. Crit Rev.Oncol.Hematol. 2008;67(3)273-278.

9. Mirici-Cappa F, Gramenzi A, Santi V, et al. Treatments for hepatocellular carcinoma in elderly patients are as effective as in younger patients: a 20-year multicentre experience. Gut 2010;59(3)387-396.

10. Strasberg SM. Nomenclature of hepatic anatomy and resections: a review of the Brisbane 2000 system. J.Hepatobiliary.Pancreat.Surg. 2005;12(5)351-355.

11. Balzan S, Belghiti J, Farges 0 , et al. The "50-50 criteria" on postoperative day 5: an accurate predictor of liver failure and death after hepatectomy. Ann.Surg. 2005;242(6)824-8, discussion.

12. Dindo D, Demartines N, Clavien PA. Classification of surgical complications: a new proposal with evaluation in a cohort of 6336 patients and results of a survey. Ann.Surg. 2004;240(2)205213.

13. Cho SW, Steel J, Tsung A, et al. Safety of liver resection in the elderly: how important is age? Ann.Surg.Oncol. 2011;18(4)1088-1095.

14. World population ageing. New York United Nations, 35. 2002.

15. Aapro MS, Kohne $\mathrm{CH}$, Cohen $\mathrm{HJ}$, et al. Never too old? Age should not be a barrier to enrollment in cancer clinical trials. Oncologist. 2005;10(3)198-204.

16. Bentrem DJ, Cohen ME, Hynes DM, et al. Identification of specific quality improvement opportunities for the elderly undergoing gastrointestinal surgery. Arch.Surg. 2009;144(11)1013-1020. 
17. Cook EJ, Welsh FK, Chandrakumaran K, et al. Resection of colorectal liver metastases in the elderly: does age matter? Colorectal Dis. 2012;14(10)1210-1216.

18. Schmucker DL. Age-related changes in liver structure and function: Implications for disease ? Exp.Gerontol. 2005;40(8-9)650-659.

19. Sanchez-Hidalgo JM, Naranjo A, Ciria R, et al. Impact of age on liver regeneration response to injury after partial hepatectomy in a rat model. J.Surg.Res. 2012;175(1)e1-e9.

20. James OF. Gastrointestinal and liver function of old age. Clin.Gastroenterol. 1983;12(3)671691.

21. Wynne HA, Cope LH, Mutch E, et al. The effect of age upon liver volume and apparent liver blood flow in healthy man. Hepatology 1989;9(2)297-301.

22. Yamada S, Shimada M, Miyake $H$, et al. Outcome of hepatectomy in super-elderly patients with hepatocellular carcinoma. Hepatol.Res. 2012;42(5)454-458.

23. Hanazaki K, Kajikawa S, Shimozawa N, et al. Hepatic resection for hepatocellular carcinoma in the elderly. J.Am.Coll.Surg. 2001;192(1)38-46.

24. Ide T, Miyoshi A, Kitahara K, et al. Prediction of postoperative complications in elderly patients with hepatocellular carcinoma. J.Surg.Res. 2013.

25. Adam R, Frilling A, Elias D, et al. Liver resection of colorectal metastases in elderly patients. Br.J.Surg. 2010;97(3)366-376.

26. Di BF, Berretta $M, D^{\prime}$ Amico $G$, et al. Liver resection for colorectal metastases in older adults: a paired matched analysis. J.Am.Geriatr.Soc. 2011;59(12)2282-2290.

27. Shiba $\mathrm{H}$, Ishida $\mathrm{Y}$, Wakiyama $\mathrm{S}$, et al. Negative impact of blood transfusion on recurrence and prognosis of hepatocellular carcinoma after hepatic resection. J.Gastrointest.Surg. 2009;13(9)1636-1642.

28. Gruttadauria S, Saint Georges CM, Pagano D, et al. Impact of blood transfusion on early outcome of liver resection for colorectal hepatic metastases. J.Surg.Oncol. 2011;103(2)140147.

29. Reddy SK, Barbas AS, Turley RS, et al. Major liver resection in elderly patients: a multiinstitutional analysis. J.Am.Coll.Surg. 2011;212(5)787-795.

30. Sulpice L, Rayar M, D'Halluin PN, et al. Impact of age over 75 years on outcomes after pancreaticoduodenectomy. J.Surg.Res. 2012;178(1)181-187.

31. Charlson ME, Pompei $\mathrm{P}$, Ales $\mathrm{KL}$, et al. A new method of classifying prognostic comorbidity in longitudinal studies: development and validation. J.Chronic.Dis. 1987;40(5)373-383.

32. Buntinx F, Niclaes L, Suetens C, et al. Evaluation of Charlson's comorbidity index in elderly living in nursing homes. J.Clin.Epidemiol. 2002;55(11)1144-1147.

33. Extermann M. Measuring comorbidity in older cancer patients. Eur.J.Cancer. 2000;36(4)453471. 


\section{TABLE LEGENDS}

Table 1. The indications for liver resections according to the patient age.

Table 2. The demographic characteristics and surgical data according to the patient age.

Table 3. The risk factors for postoperative mortality.

Table 4. The postoperative complications according to the patient age.

Table 5. The type of postoperative complications according to patient age.

Table 6. The risk factors for 1-year mortality.

\section{FIGURE LEGEND}

Figure 1. The impact of age on mortality. (A) perioperative mortality and (B) 1-year mortality.

Figure 2. Accuracy curve showing impact of age in mortality 
Table 1. The indications for liver resections according to the patient age

\begin{tabular}{lccc} 
& \multicolumn{3}{c}{ Age (years) } \\
& $<60$ & 60 to 74 & $>75$ \\
& $\mathrm{n}=372(\%)$ & $\mathrm{n}=477(\%)$ & $\mathrm{n}=152(\%)$ \\
\hline Liver metastases & $200(53.8)$ & $237(49.7)$ & $67(44.1)$ \\
Primary tumors & $75(20.1)$ & $205(43)$ & $64(42.1)$ \\
Benign tumor & $97(26.1)$ & $35(7.3)$ & $21(13.8)$
\end{tabular}


Table 2 . The demographic characteristics and surgical data according to the patient age.

\begin{tabular}{|c|c|c|c|c|c|}
\hline \multirow[t]{2}{*}{ Parameter } & \multirow[b]{3}{*}{$\begin{array}{l}\text { male } \\
\text { female }\end{array}$} & \multicolumn{3}{|c|}{ Age (years) } & \multirow[b]{2}{*}{$p$ value } \\
\hline & & $\begin{array}{c}<60 \\
(n=372)\end{array}$ & $\begin{array}{l}60 \text { to } 74 \\
(\mathrm{n}=477)\end{array}$ & $\begin{array}{c}>75 \\
(\mathrm{n}=152)\end{array}$ & \\
\hline Gender & & $\begin{array}{l}59.1 \% \\
40.9 \%\end{array}$ & $\begin{array}{l}75.9 \% \\
24.1 \%\end{array}$ & $\begin{array}{l}66.4 \% \\
33.6 \%\end{array}$ & $<0.001$ \\
\hline BMI & $\begin{array}{l}<25 \\
25 \text { to } 30 \\
>30\end{array}$ & $\begin{array}{l}46.2 \% \\
41.4 \% \\
12.4 \%\end{array}$ & $\begin{array}{l}26.2 \% \\
57.4 \% \\
16.4 \%\end{array}$ & $\begin{array}{l}33.6 \% \\
54.6 \% \\
11.8 \%\end{array}$ & $<0.001$ \\
\hline Cirrhosis & $\begin{array}{l}\text { no } \\
\text { yes }\end{array}$ & $\begin{array}{c}91.4 \% \\
8.6 \%\end{array}$ & $\begin{array}{l}84.7 \% \\
15.3 \%\end{array}$ & $\begin{array}{c}90.1 \% \\
9.9 \%\end{array}$ & 0.008 \\
\hline Portal vein embolization & $\begin{array}{l}\text { no } \\
\text { yes }\end{array}$ & $\begin{array}{c}90.3 \% \\
9.7 \%\end{array}$ & $\begin{array}{l}85.7 \% \\
14.3 \%\end{array}$ & $\begin{array}{c}94.7 \% \\
5.3 \%\end{array}$ & 0.005 \\
\hline Type of resection & minor & $48.1 \%$ & $44.9 \%$ & $45.4 \%$ & 0.627 \\
\hline & major & $51.9 \%$ & $55.1 \%$ & $54.6 \%$ & \\
\hline Type of clamping & $\begin{array}{l}\text { selective } \\
\text { pedicular } \\
\text { no }\end{array}$ & $\begin{array}{c}9.4 \% \\
71.2 \% \\
19.4 \%\end{array}$ & $\begin{array}{l}11.5 \% \\
72.3 \% \\
16.1 \%\end{array}$ & $\begin{array}{c}7.9 \% \\
76.3 \% \\
15.8 \%\end{array}$ & 0.446 \\
\hline
\end{tabular}

Caval vein clamping

0.278

$\begin{array}{lccc}\text { no } & 92.2 \% & 93.3 \% & 96.1 \% \\ \text { yes } & 7.8 \% & 6.7 \% & 3.9 \%\end{array}$

\begin{tabular}{|c|c|c|c|c|c|}
\hline Perioperative radiofrequency & $\begin{array}{l}\text { no } \\
\text { yes }\end{array}$ & $\begin{array}{c}93.3 \% \\
6.7 \%\end{array}$ & $\begin{array}{c}96.2 \% \\
3.8 \%\end{array}$ & $\begin{array}{c}97.4 \% \\
2.6 \%\end{array}$ & 0.056 \\
\hline Associated colorectal resection & $\begin{array}{l}\text { no } \\
\text { yes }\end{array}$ & $\begin{array}{c}92.5 \% \\
7.5 \%\end{array}$ & $\begin{array}{c}92.5 \% \\
7.5 \%\end{array}$ & $\begin{array}{c}93.4 \% \\
6.6 \%\end{array}$ & 0.917 \\
\hline Associated vascular resection & $\begin{array}{l}\text { no } \\
\text { yes }\end{array}$ & $\begin{array}{c}97.6 \% \\
2.4 \% \\
\end{array}$ & $\begin{array}{c}98.7 \% \\
1.3 \% \\
\end{array}$ & $\begin{array}{c}96.7 \% \\
3.3 \% \\
\end{array}$ & 0.227 \\
\hline
\end{tabular}



Table 3. The risk factors for postoperative mortality.

\begin{tabular}{|c|c|c|c|c|c|c|}
\hline \multirow{2}{*}{ Parameter } & & \multicolumn{3}{|c|}{ Univariate } & \multirow[t]{2}{*}{ Multivariable } & \multirow[b]{3}{*}{$p$ value } \\
\hline & & Alive & Died & & & \\
\hline \multirow{4}{*}{ Age (years) } & & n (\%) & n (\%) & $\begin{array}{c}\mathbf{p} \\
\text { value }\end{array}$ & Odds Ratio (95\% Cl) & \\
\hline & $<60$ & $366(37.5)$ & $6(23.1)$ & \multirow[b]{3}{*}{0.045} & \multirow{3}{*}{$\begin{array}{c}1.000 \\
1.468(0.518-4.154) \\
4.751(1.498-15.066)\end{array}$} & \multirow{3}{*}{$\begin{array}{l}- \\
0.470 \\
0.008 \\
\end{array}$} \\
\hline & 60 to 74 & $465(47.7)$ & $12(46.2)$ & & & \\
\hline & $\geq 75$ & $144(14.8)$ & $8(30.7)$ & & & \\
\hline Gender & male & $661(67.8)$ & $22(84.6)$ & 0.069 & & \\
\hline \multirow{3}{*}{ BMI } & $<25$ & $341(35)$ & $7(26.9)$ & \multirow{3}{*}{0.554} & & \\
\hline & 25 to 30 & $495(50.8)$ & $16(61.5)$ & & & \\
\hline & $\geq 30$ & $139(14.2)$ & $3(11,6)$ & & & \\
\hline \multirow{2}{*}{ Cirrhosis } & no & $863(88.5)$ & $18(69.2)$ & \multirow{2}{*}{0.008} & 1.000 & - \\
\hline & yes & $112(11.5)$ & $8(30.8)$ & & $3.314(1.234-8.900)$ & 0.017 \\
\hline \multirow{3}{*}{$\begin{array}{l}\text { Preoperative } \\
\text { chemotherapy }\end{array}$} & no & $549(56.3)$ & $22(84.6)$ & \multirow{3}{*}{0.015} & & \\
\hline & old & $63(6.4)$ & $1(3.9)$ & & & \\
\hline & recent ${ }^{*}$ & $363(37.3)$ & $3(11.5)$ & & & \\
\hline \multirow{2}{*}{$\begin{array}{l}\text { Preoperative } \\
\text { arterial } \\
\text { chemoembolization }\end{array}$} & no & $932(95.6)$ & $19(73.1)$ & \multirow{2}{*}{$<0.001$} & \multirow{13}{*}{$\begin{array}{c}1.000 \\
5.487(1.969-15285)\end{array}$} & \multirow{13}{*}{$\begin{array}{c}- \\
0.001\end{array}$} \\
\hline & yes & $43(4.4)$ & 7 (26.9) & & & \\
\hline \multirow{2}{*}{$\begin{array}{l}\text { Portal vein } \\
\text { embolization }\end{array}$} & no & $871(89.3)$ & $18(69.2)$ & \multirow{2}{*}{0.005} & & \\
\hline & yes & $104(10.7)$ & $8-(30.8)$ & & & \\
\hline \multirow{3}{*}{ Type of tumor } & metastases & $498(51.1)$ & $6(23.1)$ & \multirow{3}{*}{0.015} & & \\
\hline & $\begin{array}{l}\text { Primary } \\
\text { cancer }\end{array}$ & $329(33.7)$ & $15(57.7)$ & & & \\
\hline & $\begin{array}{l}\text { Benign } \\
\text { tumor }\end{array}$ & $148(15.2)$ & $5(19.2)$ & & & \\
\hline Surgical approach & $\begin{array}{l}\text { laparotomy } \\
\text { laparoscopy }\end{array}$ & $\begin{array}{c}933(95.7) \\
42(4.3)\end{array}$ & $\begin{array}{c}26(100) \\
0(0)\end{array}$ & 0.622 & & \\
\hline \multirow{2}{*}{ Type of resection } & minor & $457(46.9)$ & $5(19.2)$ & \multirow{2}{*}{0.005} & & \\
\hline & major & $518(53.1)$ & $21(80.8)$ & & & \\
\hline & selective & $99(10.2)$ & $3(11.5)$ & & & \\
\hline Type of clamping & pedicular & 706 (72.2) & $20(77)$ & 0.76 & & \\
\hline & no & $170(17.6)$ & $3(11.5)$ & & & \\
\hline Caval vein & no & $914(93.7)$ & $20(76.9)$ & & 1.000 & \\
\hline clamping & yes & $61(6.3)$ & $6(23.1)$ & 0.006 & $6.103(2.121-17.514)$ & 0.001 \\
\hline Associated & no & $904(92.7)$ & $23(88.5)$ & 0.433 & & \\
\hline colorectal resection & yes & $71(7.3)$ & $3(11.5)$ & 0.433 & & \\
\hline Associated & no & 955 (97.9) & $26(100)$ & 1 & & \\
\hline vascular resection & yes & $20(2.1)$ & $0(0)$ & & & \\
\hline Intraoperative & no & $762(78.2)$ & $15(57.7)$ & 0013 & 1.000 & - \\
\hline blood transfusion & yes & $213(21.8)$ & $11(42.3)$ & 0.013 & $2.361(1.023-5.449)$ & 0.044 \\
\hline
\end{tabular}

${ }^{*}$ recent defined chemotherapy performed within 6 months before surgery. 
Table 4. The postoperative complications according to the patient age.

\begin{tabular}{|c|c|c|c|c|c|}
\hline & \multicolumn{5}{|c|}{ Age (years) } \\
\hline & & $<60$ & 60 to 74 & $>75$ & \\
\hline & & $\mathrm{n}=372(\%)$ & $\mathrm{n}=477(\%)$ & $(n=152)$ & $p$ value \\
\hline \multirow{2}{*}{$\begin{array}{l}\text { Postoperative } \\
\text { complication }\end{array}$} & no & $242(65.1)$ & $292(61.2)$ & 87 (57.2) & \multirow{2}{*}{0.216} \\
\hline & yes & $130(34.9)$ & $185(38.8)$ & 65 (42.8) & \\
\hline \multirow{7}{*}{$\begin{array}{l}\text { Clavien } \\
\text { classification } \\
\text { grade of } \\
\text { complications }\end{array}$} & I & $24(6.4)$ & $24(5)$ & $13(8.6)$ & \multirow{7}{*}{0.269} \\
\hline & II & $46(12.4)$ & $84(17.6)$ & $25(16.4)$ & \\
\hline & Illa & $24(6.4)$ & $29(6.1)$ & $8(5.3)$ & \\
\hline & IIllb & $21(5.6)$ & $20(4.2)$ & $6(3.9)$ & \\
\hline & $\mathrm{IVa}$ & $8(2.2)$ & $11(2.3)$ & $5(3.3)$ & \\
\hline & $\mathrm{IVb}$ & $1(0.3)$ & $5(1)$ & $0(0)$ & \\
\hline & V & $6(1.6)$ & $12(25.2)$ & $8(5.3)$ & \\
\hline
\end{tabular}


Table 5. The type of postoperative complications seen according to patient age

\begin{tabular}{|c|c|c|c|c|}
\hline Parameter & $\begin{array}{c}<60(\mathrm{n}=372) \\
\mathrm{n}(\%)\end{array}$ & $\begin{array}{c}\text { Age (years) } \\
60 \text { to } 74(\mathrm{n}=477) \\
\mathrm{n}(\%)\end{array}$ & $\begin{array}{c}>75(\mathrm{n}=152) \\
\mathrm{n}(\%)\end{array}$ & $p$ value \\
\hline Liver failure & $10(2.7)$ & $12(2.5)$ & $7(4.6)$ & 0.39 \\
\hline Postoperative ascites & $14(3.8)$ & $25(5.2)$ & $2(1.3)$ & 0.10 \\
\hline Biliary leak/fistula & $27(7.3)$ & $45(9.4)$ & $8(5.3)$ & 0.21 \\
\hline Postoperative hemorrhage & $18(4.8)$ & $11(2.3)$ & $8(5.3)$ & 0.08 \\
\hline Intra-abdominal abscess & $24(6.5)$ & $16(3.4)$ & $6(3.9)$ & 0.09 \\
\hline Wound infection & $2(0.5)$ & $5(1)$ & $2(1.3)$ & 0.62 \\
\hline Systemic infection & $28(7.5)$ & $40(8.4)$ & $13(8.6)$ & 0.88 \\
\hline Pulmonary Complication & $20(5.4)$ & $35(7.3)$ & $10(6.6)$ & 0.52 \\
\hline Urinary complication & $9(2.4)$ & $15(3.1)$ & $4(2.6)$ & 0.81 \\
\hline Deep venous thrombosis & $7(1.9)$ & $7(1.5)$ & $1(0.7)$ & 0.58 \\
\hline Major complications & $59(15.9)$ & $76(15.9)$ & $27(17.8)$ & 0.09 \\
\hline Hospital stay (days) ${ }^{\dagger}$ & $10.8 \pm 7.4$ & $12 \pm 9.2$ & $13 \pm 8.2$ & 0.02 \\
\hline
\end{tabular}

† Mean \pm Standard deviation (SD)

Major complications are defined as Clavien group $\geq$ III. 
Table 6. The risk factors for 1 -year mortality.

\begin{tabular}{|c|c|c|c|c|c|c|}
\hline & & & Univariate & & Multivariate & \\
\hline Parameter & & Alive & Died & & & \\
\hline & & n (\%) & n (\%) & $p$ value & $\begin{array}{c}\text { Odds Ratio } \\
\text { (95\% Cl) }\end{array}$ & $\begin{array}{c}p \\
\text { value }\end{array}$ \\
\hline & $<60$ & $360(38)$ & $12(21.8)$ & & 1.000 & - \\
\hline Age (years) & 60 to 74 & $448(47.4)$ & $29(52.7)$ & 0.018 & $1.636(0.787-3.403)$ & 0.188 \\
\hline & $\geq 75$ & $138(14.6)$ & $14(25.5)$ & & $2.838(1.223-6.584)$ & 0.015 \\
\hline & male & $637(67.3)$ & $46(83.6)$ & 0012 & & \\
\hline $\operatorname{sex}$ & female & $309(32.7)$ & $9(16.7)$ & 0.012 & & \\
\hline & $<25$ & $334(35.3)$ & $14(25.5)$ & & & \\
\hline BMI & 25 to 30 & $477(50.4)$ & $34(61.8)$ & 0.239 & & \\
\hline & $\geq 30$ & $135(14.3)$ & $7(12.7)$ & & & \\
\hline & no & $841(88.9)$ & $40(72.7)$ & & 1.000 & - \\
\hline Cirmosis & yes & $105(11.1)$ & $15(27.3)$ & $<0.001$ & $2.628(1.229-5.620)$ & 0.013 \\
\hline & no & $530(56)$ & $41(74.6)$ & & & \\
\hline $\begin{array}{l}\text { Preoperative } \\
\text { chemotherapy }\end{array}$ & & $62(6.6)$ & $2(3,6)$ & 0.026 & & \\
\hline & Recent $^{*}$ & $354(37.4)$ & $12(21.8)$ & & & \\
\hline Preoperative arterial & no & $\begin{array}{c}904 \\
(95.6 \%)\end{array}$ & $47(85.5)$ & 0.004 & 1.000 & - \\
\hline & yes & $42(4.4)$ & $8(14.5)$ & & $5.487(1.969-15.285)$ & 0.001 \\
\hline Portal vein & no & $846(89.4)$ & $43(78.2)$ & & & \\
\hline embolization & yes & $100(10.6)$ & $12(21.8)$ & 0.01 & & \\
\hline & metastases & $489(51.7)$ & $15(27.3)$ & & 1.000 & - \\
\hline Type of tumor & Primary cancer & $311(32.9)$ & $33(60)$ & $<0.001$ & 2.266 & 0.026 \\
\hline & Benign tumor & $146(15.4)$ & $7(22.7)$ & & 1.753 & 0.246 \\
\hline Suraical annroach & laparotomy & $904(95.7)$ & $55(100)$ & 0110 & & \\
\hline surgical approacrn & laparoscopy & $42(4.3)$ & $0(0)$ & 0.110 & & \\
\hline Tyne of resection & minor & $450(47.6)$ & $12(11.8)$ & -0001 & 1.000 & \\
\hline туре or resection & major & $496(52.4)$ & $43(78.2)$ & $<0.001$ & $3.019(1.516-60.15)$ & 0.002 \\
\hline & selective & $98(10.4)$ & $4(6.3)$ & & & \\
\hline Type de clamping & pedicular & $683(72.2)$ & $43(78.2)$ & 0.608 & & \\
\hline & no & $165(17.4)$ & $8(14.5)$ & & & \\
\hline & no & $886(93.7)$ & $48(87.3)$ & & 1,000 & \\
\hline Caval veın clampıng & yes & $60(6.3)$ & $7(22.7)$ & 0.081 & 2.301 & 0.069 \\
\hline Associated colorectal & no & $876(92.6)$ & $\begin{array}{ll}51 & (92.7)\end{array}$ & & & \\
\hline resection & yes & $70(7.4)$ & $4(7.3)$ & & & \\
\hline Associated vascular & no & $927(98)$ & $54(98.2)$ & & & \\
\hline resection & yes & $19(2)$ & $1(1.8)$ & 0 & & \\
\hline Intraoperative blood & no & $744(78.6)$ & $33(60)$ & & 1.000 & \\
\hline transfusion & yes & $202(21.4)$ & $22(40)$ & 0.00 & $2.078(1.149-3.759)$ & 0.016 \\
\hline
\end{tabular}

${ }^{*}$ recent defined chemotherapy performed within 6 months before surgery 
Figure 1

(A)

Impact of age on postoperative mortality

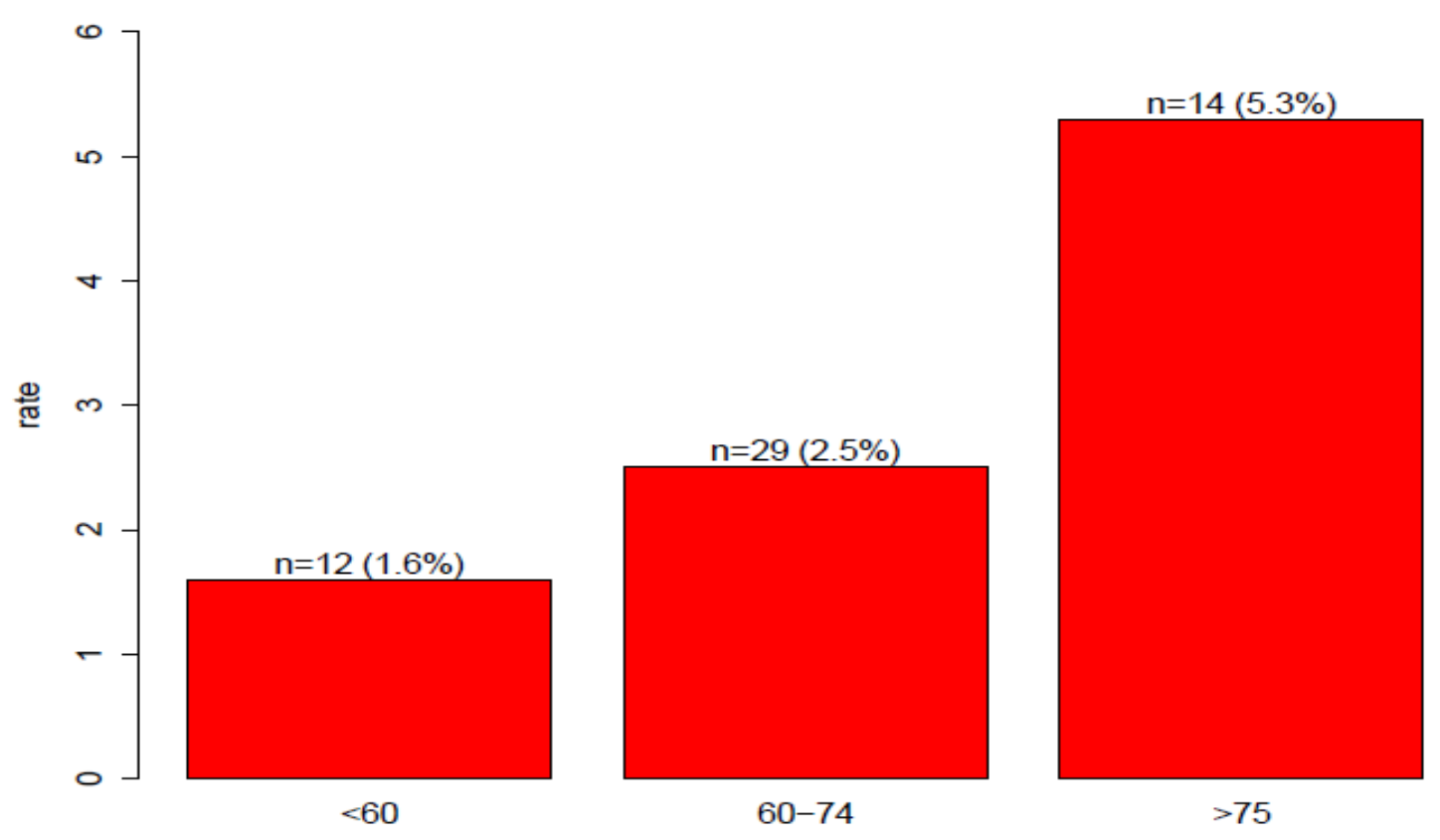

(B)

Impact of age on 1-year mortality

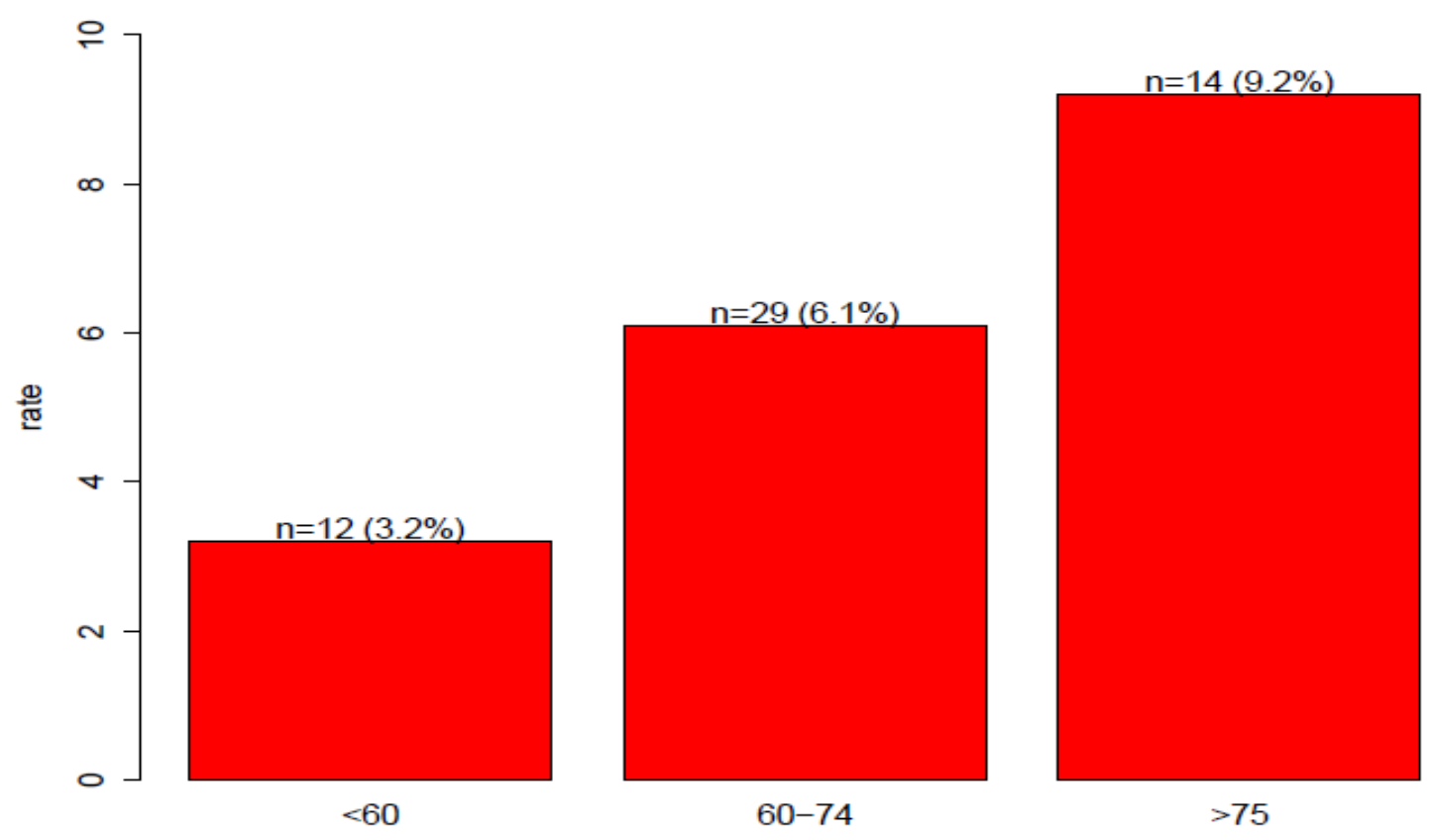


Figure 2

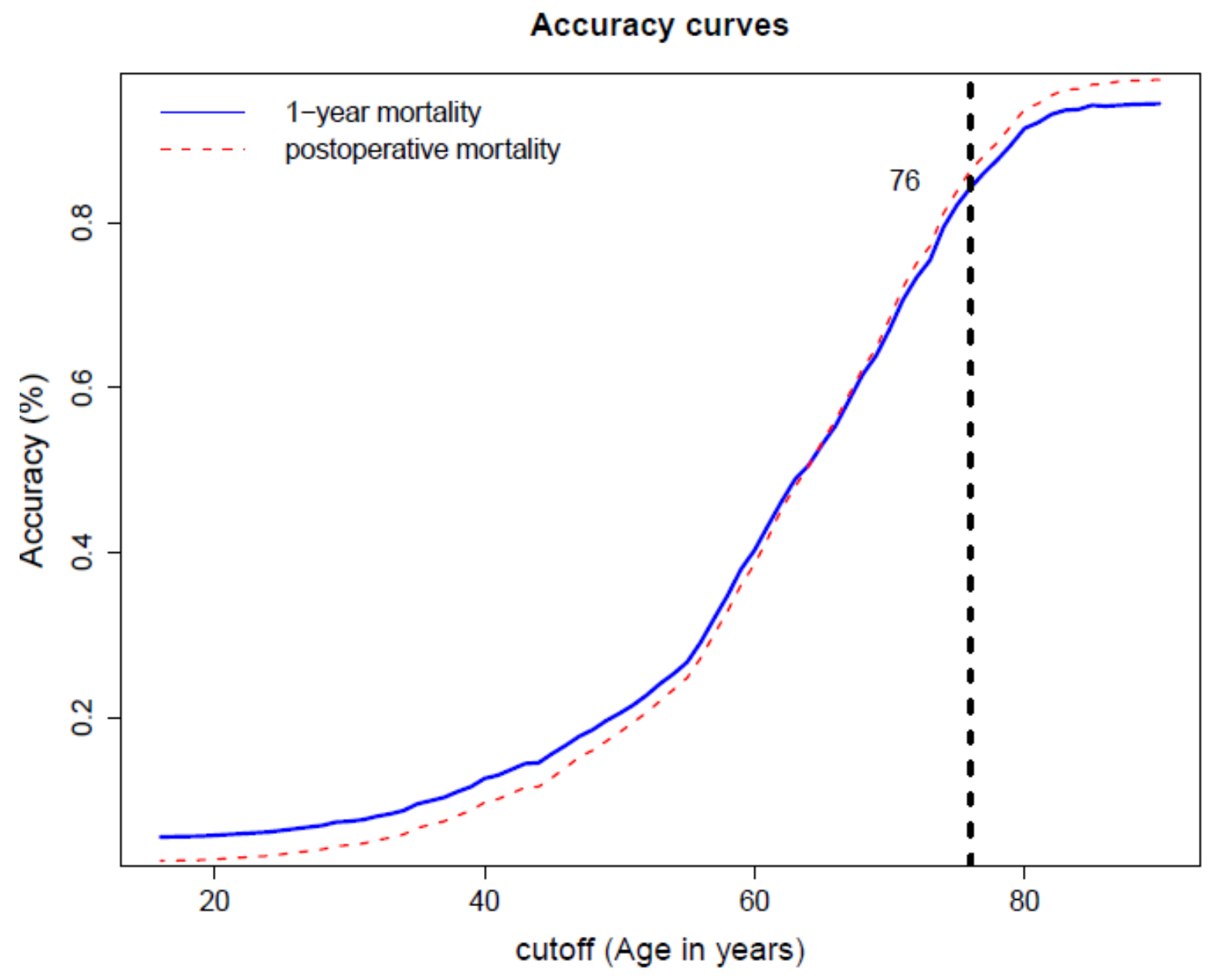

